\title{
Rebreathing method for the simultaneous measurement of oxygen consumption and effective pulmonary blood flow during exercise
}

\author{
ANDREW BUSH, CAROLYN M BUSST, SIMON JOHNSON, D M DENISON \\ From the Department of Clinical Physiology, Brompton Hospital, London
}

ABSTRACT This paper describes a rebreathing method for the simultaneous measurement of oxygen consumption $\left(\dot{\mathrm{V}}_{2}\right.$ ) and effective pulmonary blood flow (QP. eff) at rest and during exercise. Subjects rebreathed a test gas consisting of $35 \%$ oxygen, $3 \cdot 5 \%$ chlorodifluoromethane (freon- 22 ) $\stackrel{\circ}{-}$ and $10 \%$ argon in nitrogen for 30 seconds or until the respired oxygen tension fell to below $13 \cdot 3 \mathrm{kPa}_{\rightarrow}$ Sixty normal subjects were studied on a motorised treadmill, the Bruce protocol being used. The rebreathing manoeuvre was performed at three minute intervals, and was initially practised sitting down. Measurements were then made with the subjects standing at rest, and subsequently during the last minute of each stage of the Bruce exercise protocol until the subjects were exhausted. Heart rate was recorded from the electrocardiogram. Oxygen uptake plotted against calculated power (watts) showed a discontinuity between resting and exercise values, probably because power output during treadmill exercise is underestimated. The arbitrary addition of 30 watts to the exercise power outpun abolished this discontinuity. There was good agreement between rebreathing estimates of oxygen $\mathbb{Q}$ consumption and values measured during a second exercise test by the conventional open circuit argon dilution method. Coefficients of variation of oxygen consumption and effective pulmonarys blood flow measured by rebreathing were usually less than $10 \%$ even during maximal exertion. At rese mean (SD) effective pulmonary blood flow corrected for body surface area was $2 \cdot 2(0 \cdot 46) 1 / \mathrm{min} / \mathrm{m}^{2}$. Effective pulmonary blood flow rose linearly with oxygen consumption. At rest the arteriovenous oxygen content difference for pulmonary blood $\left(\dot{\mathrm{Vo}}_{2} / \mathrm{QP}_{\mathrm{P}} \mathrm{eff}\right)$ was $9 \cdot 1(1 \cdot 6) \mathrm{ml} / \mathrm{dl}$, rising to a maximum

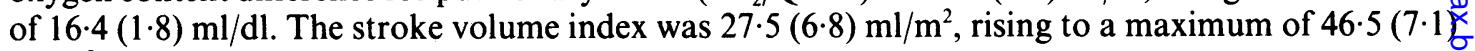
$\mathrm{ml} / \mathrm{m}^{2}$ during exertion.

If a gas that is soluble in blood is inspired, it is removed from the lung at a rate determined by that part of total pulmonary blood flow which is useful in respiratory gas exchange (effective pulmonary blood flow, QP. eff). The removal of soluble gas can be measured easily by single breath or rebreathing techniques at rest and during exercise. ${ }^{1-6}$ As lung blood flow is primarily determined by metabolic rate, it is helpful to measure the two together, so that flow can be related to oxygen uptake $\left(\mathrm{VO}_{2}\right)$ directly. This also allows the arteriovenous differences of oxygen content to be calculated for pulmonary blood. This paper describes one method of measuring oxygen uptake and effective pulmonary blood flow simultaneously.

Address for reprint requests: Dr A Bush, Department of Clinical Physiology, Brompton Hospital, London SW3 6HP.

Accepted 7 January 1988

\section{Methods}

We studied 60 normal subjects, 36 men and 24 womeno Their mean (SD) age was 38.6 (14.3), range 21-6 years; height $173.5(9.5)$, range $153-191 \mathrm{~cm}$; an ${ }^{8}$ weight $68.8(10 \cdot 3)$, range $50.0-88.1 \mathrm{~kg}$. None had ans history or physical signs of cardiorespiratory disease None had any evidence of maldistribution ventilation, as shown by an abnormal slope on the rebreathing argon trace (see below). The 21 subject席 who were 40 years of age or older had normal 12 lea $\$$ electrocardiograms at rest and on maximal exertion. 7

Each of the subjects performed an incrementa佂 exercise test on a motorised treadmill (PK Morgan) according to the Bruce protocol. ${ }^{7}$ In this test the treadmill speed and elevation is increased at the end of each three minute stage, and the subject continues to symptom limited maximum exertion. Simultaneous 
measurements of oxygen uptake and blood flow were made at rest and in the last minute of each stage of exercise. For this the subject was asked to expire to residual volume and then to rebreathe a volume of test gas slightly less than his vital capacity, from a 6 litre anaesthetic bag. The test gas was $35 \%$ oxygen, $3.5 \%$ chlorodifluoromethane (freon-22), and 10\% argon in nitrogen. The subject rebreathed at about $0.3-0.5$ cycle/s for 30 seconds or until the respired oxygen tension $\left(\mathrm{Po}_{2}\right)$ had fallen below $13.3 \mathrm{kPa}$, whichever was sooner.

A typical trace from this manoeuvre is illustrated in figure 1. It shows a rapid distribution of the insoluble argon within the bag-lung system, a linear fall in $\mathrm{Po}_{2}$, an exponential rise in carbon dioxide tension $\left(\mathrm{PCO}_{2}\right)$, and an exponential removal of the soluble freon- 22 . The end tidal points are used for all the calculations. They can be defined from the carbon dioxide trace, given an allowance for the offset of the pens. The volume of gas in the bag and the lungs combined is obtained from the fall in argon concentration. Effective pulmonary blood flow is derived from the slope of the logarithm of freon concentration.' The Bunsen solubility coefficients in both blood and tissue of argon and freon-22 were respectively assumed to be 0.0 and $0.83 \mathrm{ml}$ per ml per atmosphere at $37^{\circ} \mathrm{C}$. The freon trace was extrapolated back to $0 \cdot 1$ second after the start of

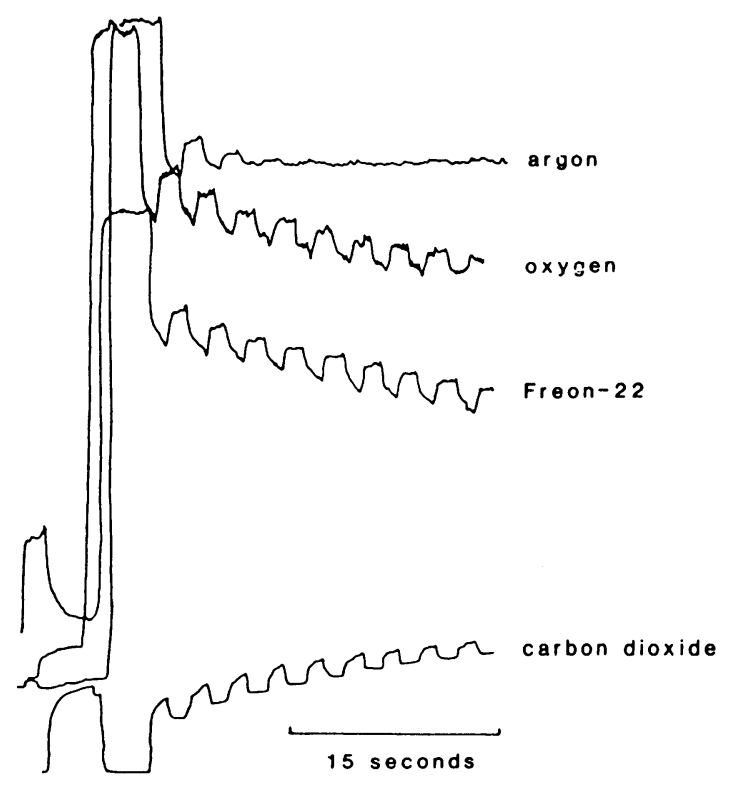

Fig 1 Typical trace from the rebreathing manoeuvre (pens slightly offset). The $x$ axis is time (seconds) and the $y$ axis shows the output from the mass spectrometer in arbitrary units, which can be converted to partial pressures with an appropriate calibration curve. inspiration, and this was assumed to be zero time in the calculations. Recirculation of freon-22 is apparent from any reduction in slope late in the rebreathing period, and any such portions of the curves were rejected. We did not calculate lung tissue volumes, because in the past we have found the measurement to be poorly reproducible with this technique. ${ }^{4}$ Possible reasons for this have been discussed elsewhere. ${ }^{3}$ Oxygen uptake is derived from the linear fall in oxygen concentration. In each case the slopes were inspected and the initial linear portion was selected by eye. Corrections for slight progressive changes in bag-lung volume are made from the small alterations in argon concentration. The rebreathing bag temperature is assumed to be $30^{\circ} \mathrm{C} .^{8}$ A full description of these calculations is given in the appendix.

In all of the rebreathing studies the subjects performed a sequence of at least seven manoeuvres at three minute intervals while standing at rest. The first three were discarded because they were consistently higher than the other resting measurements, as found by others. ${ }^{4}$ The baseline was taken as the mean of at least three technically satisfactory manoeuvres. The mean bag-lung volume was calculated, and any subsequent exercise measurement in which this volume deviated by more than $10 \%$ from the resting value was rejected. This was necessary in only a few of the manoeuvres towards the end of exercise, when some subjects were too breathless to keep a tight seal around the mouthpiece. The mechanical power load was calculated for each subject from the equation

Power(watts) $=$ body wt $(\mathrm{kg}) \times 9.81 \times$

sine(angle of tilt) $\times$ treadmill $\operatorname{speed}(\mathrm{m} / \mathrm{s})$.

The arteriovenous oxygen content difference was obtained as the quotient $\dot{V}_{2} / \dot{Q} \mathbf{P}$. eff.

\section{STUDY PROTOCOLS}

All exercise tests were carried out after the subjects had been familiarised with the equipment and had rested for at least 10 minutes. Food and drinks other than water were prohibited in the hour before the test. All procedures were approved by the hospital ethics committee, and all subjects gave informed consent.

In the first study 20 normal people performed two exercise tests, separated by at least two days, in random order. In one test oxygen uptake was measured by the open circuit, argon dilution method in routine use in our laboratory, ${ }^{9}$ and in the other by the rebreathing method described above. In a second study four normal men performed five exercise tests over a three week period to assess the reproducibility of the rebreathing technique. All had previously performed many exercise tests. In a third study 40 subjects performed a single exercise test with simultaneous measurement of oxygen uptake and effective pulmonary blood flow by the rebreathing technique. 
Oxygen uptake (open circuit, $1 / \mathrm{min}$ )

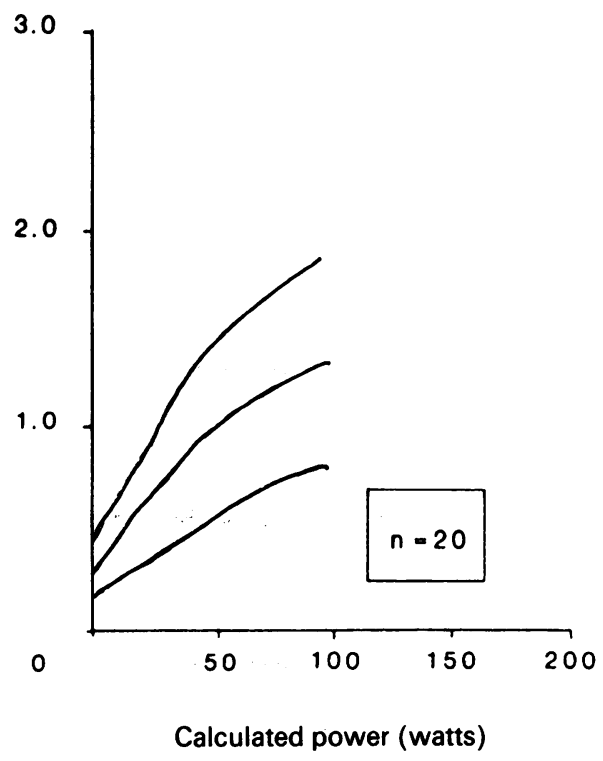

Fig 2 Open circuit, argon dilution oxygen consumption plotted against calculated work in 20 normal subjects who performed a Bruce protocol exercise test (mean with $2 S D$ ). The discontinuity corresponds to the stage 1 measurement.

Oxygen uptake (open circuit $1 / \mathrm{min}$ )

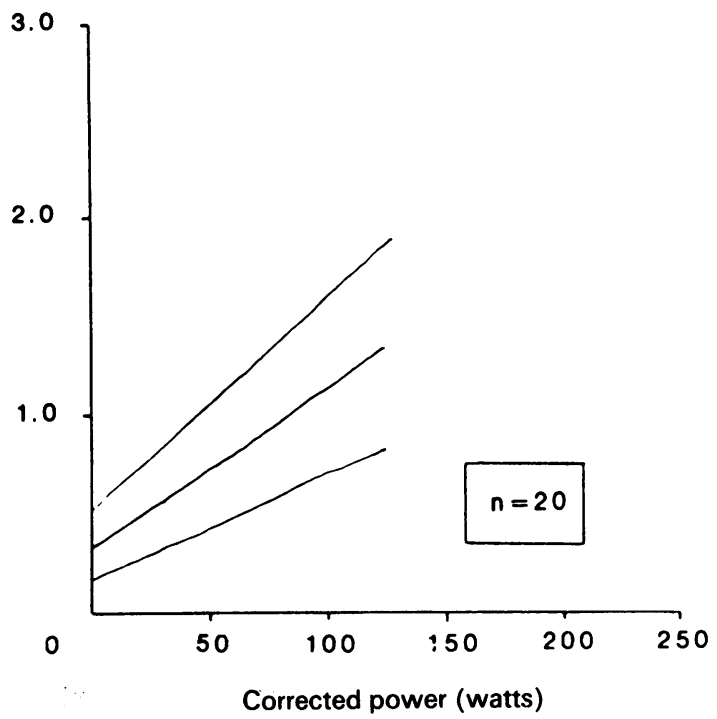

Fig 3 Open circuit, argon dilution oxygen consumption plotted against corrected work (calculated work +30 watts) in 20 patients performing the Bruce protocol (mean with $2 S D)$. The relationship is linear.

\section{Results}

Open circuit estimates of oxygen uptake against calculated mechanical power load are plotted in figure 2 , which shows a discontinuity between resting and exercising values. We believe that this occurs because the calculation of power loads imposed by the \& treadmill neglects energy expended in walking on a horizontal (as distinct from an inclined) plane. If this is assumed to be an additional 30 watts at all levels of $\vec{\omega}$ exertion, the relation between oxygen uptake and power load becomes linear as in figure 3 . This arbitrary $\overrightarrow{\vec{x}}$ estimate of the additional work corresponds with the results of previous studies on the energy cost of walking on flat planes. ${ }^{10}$ " An arbitrary estimate has to ${ }^{N}$ be used because there are no equations for calculating $\infty$ additional work on the basis of easily made 의 measurements such as weight or body surface area.

The main purpose of the first study was to compare $\frac{D}{0}$ rebreathing and open circuit estimates of oxygen uptake. These are plotted in figure 4 , which is based on $\vec{\oplus}$ 80 observations in the 15 subjects for whom three $\infty$ point oxygen calibrations were available. The regression of rebreathing estimate $\left(\dot{\mathrm{Vo}}_{2} \mathrm{rb}\right)$ on the open circuit value $\left(\dot{\mathrm{V}}_{2} \mathrm{Oc}\right)$ is $\dot{\mathrm{Vo}}_{2} \mathrm{rb}=0.92 \times \dot{\mathrm{Vo}}_{2} \mathrm{Oc}+0.20$ $1 / \mathrm{min}: r=0.979$, standard error of the estimate $=$ $0.17 \mathrm{l} / \mathrm{min}$. The relation between the two

Rebreathing oxygen uptake $(\mathrm{ml} / \mathrm{min})$

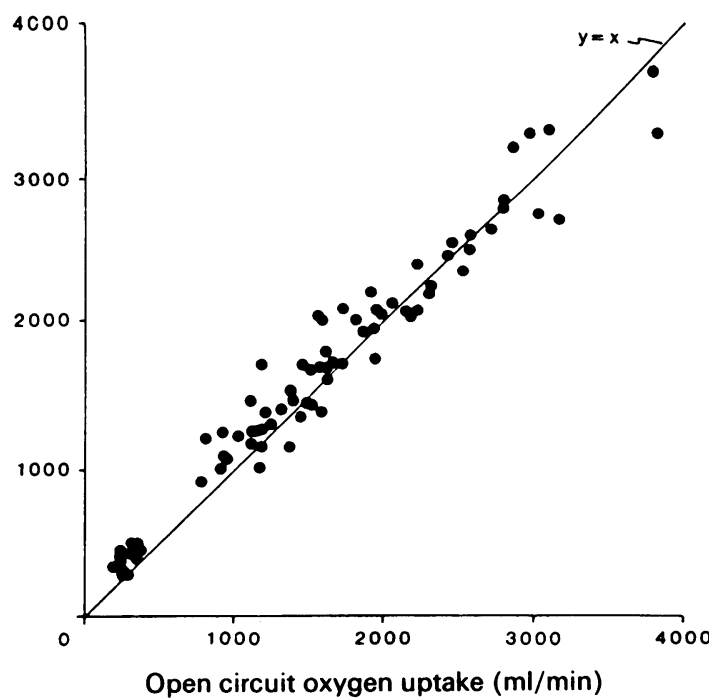

Fig 4 Comparison of rebreathing and open circuit, argon dilution oxygen uptakes during two separate Bruce protocol exercise tests: 80 observations on 15 subjects. The line of identify is plotted. 
OP. eff $(1 / \mathrm{min})$

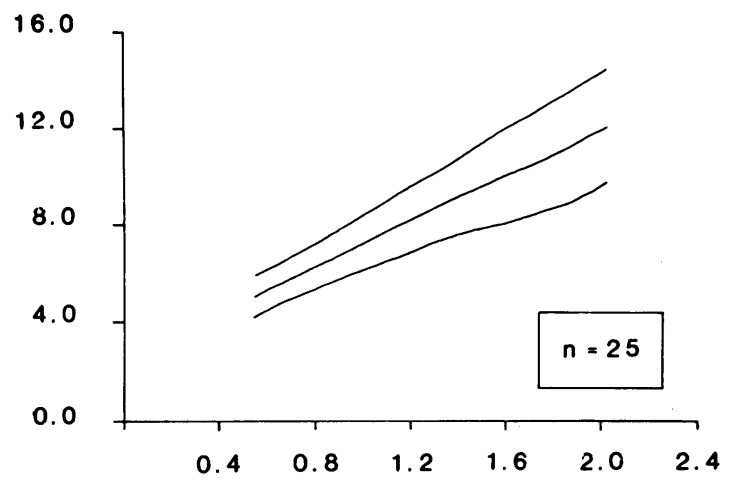

$\dot{\mathrm{V}}_{2}$ (rebreathing, $\left.1 / \mathrm{min}\right)$

Fig 5 Effective pulmonary blood flow ( $\dot{Q}_{P .}$ eff) plotted against rebreathing estimates of oxygen consumption in the 25 normal subjects who attained an oxygen uptake of at least $2.0 \mathrm{l} / \mathrm{min}$ (mean with.2SD). The relationship is linear.

Arteriovenous oxygen content differences $(\mathrm{ml} / \mathrm{dl})$

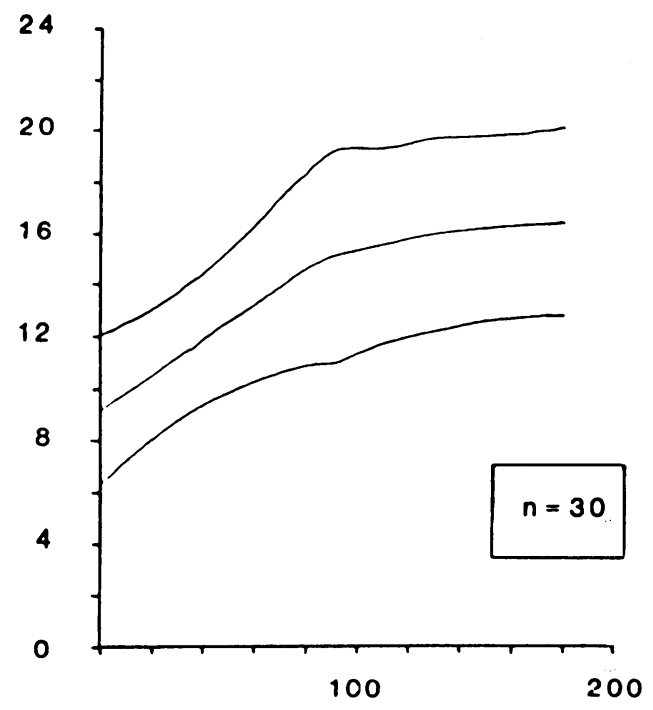

Corrected work (watts)

Fig 6 Arteriovenous oxygen content differences plotted against corrected work (calculated work +30 watts) in the 30 subjects who performed at least two stages of the Bruce protocol (mean with $2 S D$ ). The relationship is curvilinear.

measurements is linear and close to identity. With the subjects at rest the rebreathing method overestimated oxygen uptake slightly, but the difference became progressively less as exercise proceeded.

In the second study four men exercised on five occasions over a three week period to check the variability of the rebreathing procedure. The mean (range) of coefficients of variation (\%) at rest and on exercise were as follows: bag-lung volume at rest $2 \cdot 1$ $(0 \cdot 8-2 \cdot 9)$ and during exercise $1 \cdot 7(0 \cdot 7-3 \cdot 4)$; rebreathing oxygen consumption at rest $8.4(4.9-11.3)$ and during exercise 4.9 (2.4-8.1); and effective pulmonary blood flow at rest $6.0(3 \cdot 2-9.0)$ and during exercise 3.2 $(0 \cdot 9-8 \cdot 5)$.

Finally, 40 subjects performed the combined rebreathing procedure that measured effective pulmonary blood flow and metabolic uptake simultaneously. Figure 5 shows the results obtained in the 25 subjects who attained an oxygen uptake of at least $2.0 \mathrm{l} / \mathrm{min}$. The relation between effective pulmonary blood flow and oxygen uptake is linear, with a mean (SD) slope of $5.1(0 \cdot 8)$. The mean (SD) resting effective pulmonary blood flow corrected for surface area was $2.20(0.46) \mathrm{l} / \mathrm{min} / \mathrm{m}^{2}$ (60 subjects). There was a significant inverse correlation with age (surface area corrected effective pulmonary blood flow $=-0.015$ age $+2.77 ; \mathrm{r}=-0.43, \mathrm{p}<0.001)$ and it was greater in men than in women (mean (SEM) difference $\left.0.37(0.11) 1 / \mathrm{min} / \mathrm{m}^{2} ; \mathrm{p}<0.002\right)$. The mean (SD) slope of increase of effective pulmonary blood flow during exercise (rest values being omitted) was $0.0363(0.0135) 1 / \mathrm{min} /$ watt; there were no sex differences, but the slope showed a weak positive correlation with age $($ slope $=(0.029 \times$ age $)+0.025$; $r=0.29, p<0.05$ ).

Figures 6-9 show the changes in the arteriovenous oxygen content differences and cardiac stroke volume index that occurred during the treadmill test. The two variables have been plotted against a power load scale that has been corrected as indicated in the first paragraph of this section (figs 6 and 8), and also against rebreathing oxygen uptake (figs 7 and 9). Both tend to a maximum that is reached, or very nearly reached, by the end of the third or fourth stage of exercise.

At rest the mean (SD) arteriovenous oxygen content difference was $9 \cdot 1(1.6) \mathrm{ml} / \mathrm{dl}$, with no sex or age related differences. During exercise the mean maximal value was $16.5(1.8)$, with a greater rise in men than in women (mean (SEM) difference $1.3(0.6) \mathrm{ml} / \mathrm{dl}$; $\mathrm{p}<0.05)$ but there were no significant changes related to age. The mean resting stroke volume index was $27 \cdot 5$ $(6.8) \mathrm{ml} / \mathrm{m}^{2}$, greater in men than in women (mean (SEM) difference $\left.5.1(1.8) \mathrm{ml} / \mathrm{m}^{2} ; \mathrm{p}<0.01\right)$. There was a trend for an inverse correlation of stroke volume with age, but this did not reach significance $(r=-0.20, p<0.20)$. The index rose to a mean of $46.5(7 \cdot 1) \mathrm{ml} / \mathrm{m}^{2}$, and this rise was independent of age and sex. 
Arteriovenous oxygen content differences ( $\mathrm{ml} / \mathrm{dl}$ )

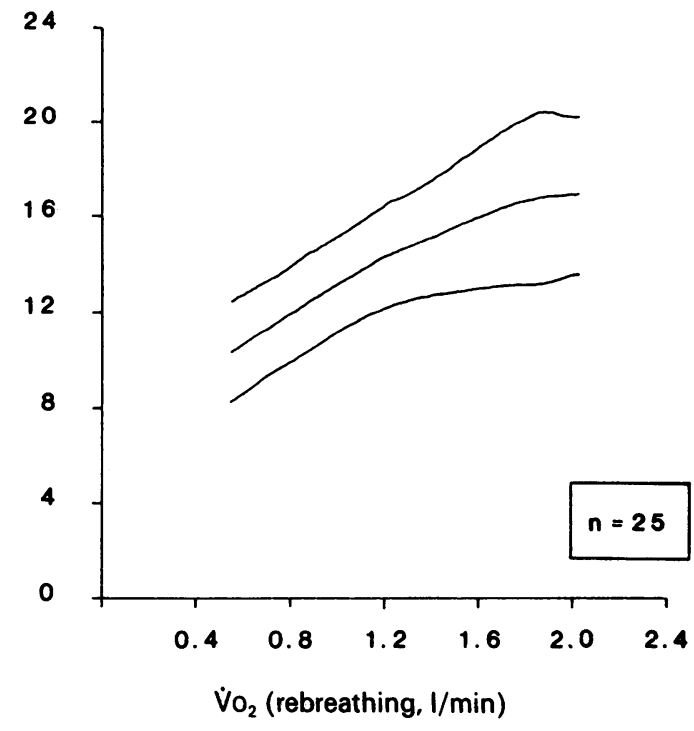

Fig 7 Arteriovenous oxygen content differences plotted against rebreathing oxygen uptake in the 25 subjects who attained an oxygen uptake of at least $2.0 \mathrm{l} / \mathrm{min}$ (mean with 2 $S D)$. The relationship is curvilinear and similar to that shown in figure 6.

Stroke volume index $\left(\mathrm{ml} / \mathrm{m}^{2}\right)$

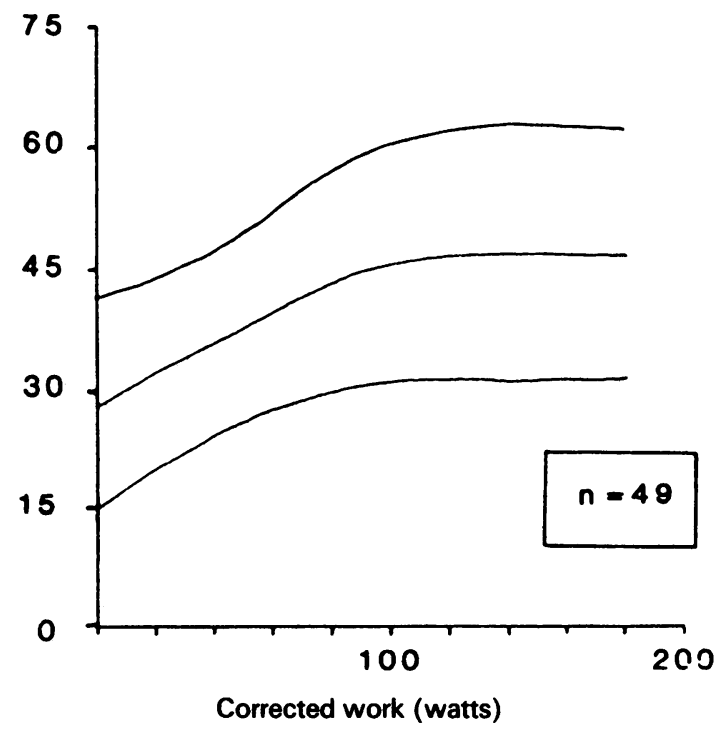

Fig 8 Stroke volume index plotted against corrected work (calculated work +30 watts) in 49 subjects who performed at least two stages of the Bruce protocol exercise test (mean with $2 S D)$. The relationship is curvilinear.
Stroke volume index $\left(\mathrm{ml} / \mathrm{m}^{2}\right)$

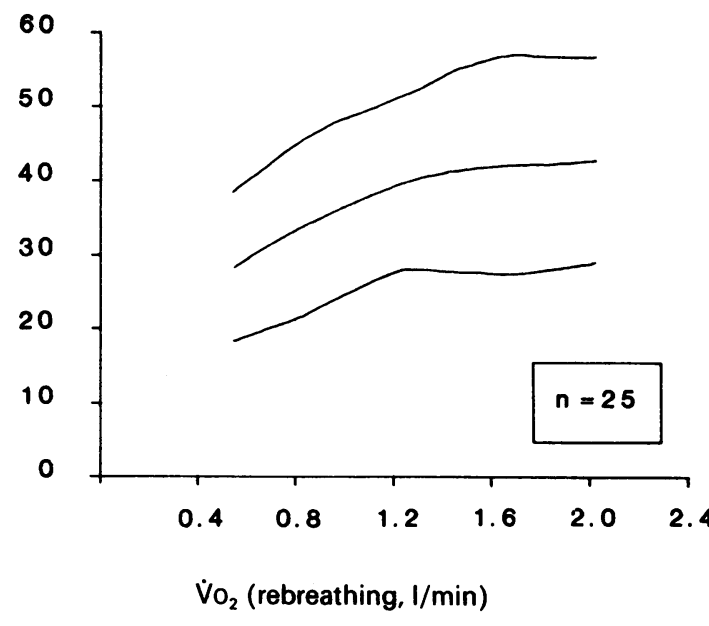

Fig 9 Stroke volume index plotted against rebreathing oxygen uptake in the 25 subjects who attained an oxygen uptake of at least $2.0 \mathrm{l} / \mathrm{min}$ (mean with 2 SD). The relationship is curvilinear and similar to that shown in figure 8 .

\section{Discussion}

This paper reports the response of effective pulmonary blood flow to treadmill exercise in healthy subjects. The use of the treadmill rather than a bicycle ergometer introduces a problem of calculating external work. The conventional calculation $(=$ wt $\times 9.81 \dot{\sigma}$ $\times$ sine (angle of tilt) $\times$ treadmill speed) does not yield 3 . the expected linear relationship when power output is $\delta$ plotted against oxygen uptake. The calculation is of $₹$ power output in the vertical direction only, and $\mathrm{O}$ neglects swinging of the limbs and internal friction. For example, a subject sprinting on the flat would be calculated as doing no work. The present data suggested that adding 30 watts to calculated work for each o stage of exertion (cf rest) restored the linear relation- $N$ ship. This value accords with other estimates of work $\mathbb{N}^{-}$ done by walking on a horizontal plane (50 watts 0 walking on the flat at $\left.5.6 \mathrm{~km} / \mathrm{h}^{10}\right)$. As power output 0 varies with body weight and speed, ${ }^{11}$ however, a single $\frac{\mathscr{\complement}}{\mathscr{C}}$ correction factor applied to all individuals is likely to $\stackrel{\mathcal{P}}{?}$ lead to errors. Pulmonary blood flow during exercise 0 may therefore best be plotted against oxygen uptake.

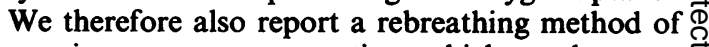
measuring oxygen consumption, which can be com- $\mathbb{\mathbb { D }}$ bined with measurement of effective pulmonary blood flow. Comparison with the conventional open circuit argon dilution method" showed that the rebreathing 
estimate is slightly but significantly greater at rest. This difference became progressively less as exercise proceeded. At rest the rebreathing manoeuvre may cause a transient increase in pulmonary blood flow (although this is disputed) and blood volume. ${ }^{12-14}$ This will lead to a temporary increase in oxygen uptake in the lungs, although systemic oxygen usage will be little changed. As exercise progresses, the pulmonary capillary volume expands and hyperventilation causes progressively less further expansion, ${ }^{14}$ particularly as the rebreathing and spontaneous breathing patterns become more similar. ${ }^{15}$

There have been many previous studies in which inert gases have been used to measure effective pulmonary blood flow, capillary volume, and lung tissue volume at rest and during exercise. ${ }^{1-6}$ Good agreement has been found between inert gas determinations of flow and cardiac output measured by dye dilution, ${ }^{21617}$ the direct Fick principle, ${ }^{1819}$ and the Doppler effect. ${ }^{20}$ Many workers have reported the relation between cardiac output and oxygen consumption. Pooled data from studies on supine subjects ${ }^{21}$ give a relationship of

$$
Q=\left[6 \times \dot{V}_{2}\right]+6.0(1 / \mathrm{min}) \text {. }
$$

During upright exercise blood flow is known to be some 2 litres/min lower for a given oxygen consumption. ${ }^{22}$ We found the slope of the relation between effective pulmonary blood flow and oxygen consumption to be $5 \cdot 1(1 / \mathrm{min} / 1 / \mathrm{min})$; similar slopes $(4 \cdot 6,4 \cdot 72,6 \cdot 01)$ have been reported by others. ${ }^{23-25}$ The intercept was $2.14 \mathrm{l} / \mathrm{min}$; previously reported intercepts are much higher $(5 \cdot 31,4 \cdot 07,3 \cdot 58)$. One possible explanation is that previous workers made invasive measurements, and apprehension may have increased cardiac output more than oxygen consumption. ${ }^{26}$ Another is that we ensured a truly basal state by making our subjects stand for at least 20 minutes before starting exercise, whereas others deliberately avoided a prolonged rest before subjects started on the treadmill.

The simultaneous measurement of oxygen consumption and effective pulmonary blood flow allows estimation of arteriovenous oxygen content differences $\left(\mathrm{AVO}=\dot{\mathrm{VO}}_{2} / \mathrm{QP}_{\mathrm{P}}\right.$ eff). Some workers have reported that this rose linearly with work ${ }^{2728}$ but this is at variance with our findings (fig 6) and with theoretical considerations: if oxygen consumption and cardiac output are linearly related to work - that is,

$$
\dot{\mathrm{Vo}}_{2}=\mathrm{ml} . \mathrm{W}+\mathrm{cl}
$$

and QP. eff $=\mathrm{m} 2 . \mathrm{W}+\mathrm{c} 2$ (where $\mathrm{m} 1, \mathrm{~m} 2$ are the slopes and $\mathrm{cl}, \mathrm{c} 2$ the intercepts of the appropriate linear regression equations)-

then $A V O=(\mathrm{m} 1 . W+\mathrm{c} 1) /(\mathrm{m} 2 . \mathrm{W}+\mathrm{c} 2)$ W)

and (with numerator and denominator divided by

$$
\operatorname{AVO}=(\mathrm{m} 1+\mathrm{cl} / \mathrm{W}) /(\mathrm{m} 2+\mathrm{c} 2 / \mathrm{W})
$$

Thus as $\mathrm{W}$ becomes large relative to the intercepts $\mathrm{cl}$ and $\mathrm{c} 2$, the arteriovenous oxygen content difference tends to a maximum value of $\mathrm{m} 1 / \mathrm{m} 2$. The curvilinear relationship we report therefore is exactly what would be predicted from the well established linear relation between power output and oxygen uptake and between power output and cardiac output. The greater arteriovenous oxygen content differences found in men have been reported before, and are attributed to the higher resting haemoglobin concentration in men. ${ }^{29}$

Simultaneous measurement of heart rate also allows estimation of stroke volume index at rest and on exercise. As anatomical shunt is not measured stroke volume is underestimated, but the error will be less than $5 \%$ in people with normal central circulations. ${ }^{30}$ The percentage increase reported here is similar to that found by the Doppler technique $(167 \%)$ and the dye dilution method $(184 \%)$ in other treadmill studies. ${ }^{31} 32$

In summary, this rebreathing test allows simultaneous measurement of effective pulmonary blood flow and oxygen consumption. We have used it to study effective pulmonary blood flow, arteriovenous oxygen content differences, and stroke volume index. The last two measurements have maxima that appear to be reached during submaximal exercise and may be of particular value in studying patients.

$A B$ is supported by the British Heart Foundation.

\section{Appendix}

MEASUREMENT OF BAG-LUNG VOLUME AND EFFECTIVE PULMONARY BLOOD FLOW

The formal derivation of these equations has been published in full elsewhere. ${ }^{333}$ This appendix describes only the steps in the computerised calculations. They are made with the hospital mainframe computer (Prime 750), as described previously. ${ }^{33}$ The paper trace is placed on a digitising table (Tektronix Ltd) linked to a graphics terminal. The data are entered by successively digitising the end tidal point immediately before the vital capacity inspiration of test gas; the height of the initial plateau before the rebreathing; and successive end tidal points during rebreathing. The end tidal points during rebreathing are defined by first marking on the carbon dioxide trace the points at the end of each expiration, immediately before the rapid downstroke of the trace caused by the next inspiration. The end tidal points for argon, freon22 , and (for measurement of oxygen uptake) oxygen are measured at the corresponding time points on the appropriate trace, with an allowance for the offset of the pens. This is done by hand on a drawing board with sliding adjustable rulers. The digitisation is carried out first for argon and then for freon.

The initial step is to align the argon and freon traces (that is, to correct for the offset of the pens), and scale each to a maximum of 100 . If gas( $(\mathrm{IH})$ is the maximum height of the trace of that gas - that is, the height of the initial plateauthen 


$$
\operatorname{Gas}(\mathrm{H})=\operatorname{gas}(\mathrm{H}) \times 100 / \operatorname{gas}(\mathrm{IH}),
$$

where gas $(\mathrm{H})$ is the digitised height of the trace at each successive end tidal point. The two normalised traces are displayed and plotted against time, and the operator marks with a cursor the position on the argon trace by which he judges gas mixing to be complete, $\operatorname{Ar}(\operatorname{mix})$. A new curve is generated from the equation

$$
\operatorname{Frcorr}(t)=100 \times \text { freon }(t) / \operatorname{argon}(t),
$$

where $\operatorname{Frcorr}(t)$, freon $(t)$, and $\operatorname{argon}(t)$ are respectively the heights at time $t$ of the new (corrected freon) curve, and the previously normalised freon and argon curves. VAO (the combined bag-lung volume) is calculated from the equation

$$
\text { VAO }=\mathrm{K} \times(\text { bag volume }) /(\operatorname{Ar}(\mathrm{mix}),
$$

where $K$ is the ATPD to BTPS conversion factor. The next step is the logarithmic (base 10) transform, also expressed as a percentage):

$$
\operatorname{Frcorr}(t)=\log (10)[\operatorname{Frcorr}(t)]-2 \cdot 0 .
$$

This new curve is displayed by the computer. Zero time (ZT) is nominated as 100 milliseconds after the onset of the rapid vital capacity inspiration at the start of the manoeuvre. A suitable linear portion of the trace, after gas mixing is complete, is then analysed. Linear regression is used to find the slope (S) and the $y$ intercept (YINT) of this trace. Then:

$\mathrm{Z0}=-0.434297(\mathrm{~S} \times 60)$ [conversion to natural logarithms]

$\mathrm{Zl}=10^{(\mathrm{S} \times \mathrm{ZT}+\mathrm{YINT})}$

$\mathrm{Z} 2=(1-\mathrm{Zl}) /(\alpha \mathrm{W} \times \mathrm{Zl})$

QPeff $=$ VAO $\times 100 \times(1+\alpha w \times Z 2) /(\alpha b \times Z 0)$,

where $\alpha b, \alpha w$ are respectively the Bunsen solubility coefficients of freon-22 in blood and water, both equal to 0.83 per $\mathrm{ml}$ per atmosphere, at $37^{\circ} \mathrm{C}$.

A full listing of this FORTRAN program has been published ${ }^{33}$ and may be obtained from the authors.

\section{MEASUREMENT OF OXYGEN CONSUMPTION}

The amount of oxygen present in the system during rebreathing, after gas mixing is complete, is given by the product of the volume of the system and the percentage of oxygen present.

$\dot{\mathrm{Vo}}_{2}=$ [rate of fall in system $\mathrm{O}_{2}$ content $] \times[$ STPD correction]-that is,

$\dot{\mathrm{VO}}_{2}=\left[(\mathrm{PAr0} . \mathrm{VB} / \mathrm{PB}) \cdot \mathrm{d}\left(\mathrm{Po}_{2} / \mathrm{PAr}\right) / \mathrm{dt}\right] \times[273 \cdot \mathrm{PB} /(\mathbf{7 6 0} .(273$ $+30)$ )],

where PAr0 is the initial argon tension in the bag; $\mathrm{PAr}, \mathrm{Po}_{2}$ are respired argon and oxygen tensions at any instant; $V_{B}$ is the initial bag volume (ATP); and PB is barometric pressure. Barometric pressure cancels out in the above equation, but is shown for clarity; the temperature of the gas in the rebreathing bag is assumed to be $30^{\circ} \mathrm{C}{ }^{8}$ The same steps were repeated for each manoeuvre. Firstly, a calibration curve relating height of the oxygen trace above an arbitrary baseline has to be constructed. For each of the three points (air and 15\% and $35 \%$ oxygen) the mean of the heights before and after the manoeuvre is plotted against $\mathrm{Po}_{2}$. A correction for water vapour pressure in room air is made on the basis of tables. ${ }^{34}$ Simple linear regression is used to find the coefficients of the equation of the line of best fit. The height of successive end tidal points for oxygen (above the same baseline) and the corresponding argon heights (the horizontal line through the end tidal values immediately before rebreathing being used as $\overrightarrow{\vec{F}}$ the baseline) are measured on a drawing board with sliding $\stackrel{\vec{P}}{+}$ adjustable rulers. The time of these points from any convenient time zero and the height of the inspired argon plateau (Ari) are also measured. The oxygen heights are converted to $\bar{\sigma}$ partial pressures by using the previously calculated $\vec{\Phi}$ coefficients of the calibration equation, and divided by the corresponding argon heights. These derived points $\left(\mathrm{Po}_{2}(t) / \infty\right.$ $\operatorname{Ar}(t))$ are plotted against time, and the linear portion of this $\overrightarrow{0}$ graph is selected. The slope of this line is found, again by $\overrightarrow{\vec{H}}$ means of linear regression, and hence oxygen consumption is $\vec{\omega}$ calculated with the above equation. These calculations can be performed on a hand held calculator with linear regression $\vec{x}$ programmed in or as an intrinsic function (T166, Texas Instuments). Alternatively, a FORTRAN program may be obtained from the authors.

\section{References}

1 Cander L, Forster RE. Determination of pulmonary $\frac{D}{O}$ tissue volume and pulmonary capillary blood flow in man. J Appl Physiol 1959;14:541-51.

2 Sackner MA, Greeneltch D, Heiman MS, Epstein S, Atkins N. Diffusing capacity, membrane diffusing capacity, capillary blood volume, pulmonary tissue volume and cardiac output measured by a rebreathing technique. Am Rev Respir Dis 1975;111:157-65.

3 Denison DM, Davies NJH, Brown DJ. A theoretical comparison of single breath methods of studying $\mathbb{D}$ soluble gas exchange in the lung. In: Cumming $\mathbf{G}$, Bonsignore G, eds. Pulmonary circulation in health and $\overline{\mathrm{O}}$ disease. New York: Plenum Press, 1980:139-65.

4 Waller JF. Assessment of a single breath test of whole and regional lung function in man. MD thesis, University of London, 1982.

5 Bowyer JJ. The non-invasive measurement of pulmonary blood flow in children. DM thesis, University of Oxford, 1983.

6 Elkanayam U, Wilson AF, Morris J, et al. Non-invasive measurement of cardiac output by a single breath constant expiratory technique. Thorax 1984;39: 107-13.

7 Bruce RA. Exercise testing of patients with coronary heart disease. Ann Clin Res 1971;3:323-32.

8 Denison DM. Mixed venous blood gas-tensions and respiratory stress in man. PhD thesis, University of London, 1968.

9 Davies NJH, Denison DM. The measurement of $\mathrm{N}$ metabolic gas exchange and minute volume by mass $N$ spectrometry alone. Respir Physiol 1979;36:261-7.

10 Jones NL, Campbell EJM. Clinical exercise testing. 2nd ed. Philadelphia: WB Saunders, 1980.

11 Passmore R, Durnin JVGA. Human energy expenditure. Physiol Rev 1955;35:801-40.

12 Armitage GH, Arnott WM. Effect of voluntary hyperpnoea on pulmonary blood flow. $J$ Physiol: 1949;109:64-9.

13 Matalon S, Dashkoff N, Nesarajah MS, Klocke FJ, Farhi LE. Effects of hyperventilation on pulmonary blood flow and recirculation time of humans. J Appl Physiol 1982;52:1161-6.

14 Anderson TW, Shepard RJ. The effects of hyperventila- 
tion and exercise upon the pulmonary diffusing capacity. Respiration 1968;25:465-84.

15 Jones NL, McHardy GJR, Naimark A, Campbell EJM. Physiological deadspace and alveolar-arterial gas pressure differences during exercise. Clin Sci 1966;31:19-29.

16 Ayotte B, Seymour J, Mcllroy MB. A new method for measurement of cardiac output with $\mathrm{N}_{2} \mathrm{O}$. $J$ Appl Physiol 1970;28:863-6.

17 Teichman.J, Adaro F, Veicsteinas A, Cerretelli P, Piiper J. Determination of pulmonary blood flow by rebreathing of soluble inert gases. Respiration 1974;31:296-309.

18 Becklake MR, Varvis CJ, Pengelly LD, Kenning S, McGregor M, Bates DV. Measurement of pulmonary blood flow during exercise using nitrous oxide. $J$ Appl Physiol 1962:17:579-86.

19 Zeidifard E, Godfery S, Davies EE. Estimation of cardiac output by an $\mathrm{N}_{2} \mathrm{O}$ rebreathing method in adults and children. J Appl Physiol 1976;41:433-8.

20 Mehta N, Iyawe VI, Cummin ARC, Bayley S, Saunders $\mathrm{KB}$, Bennett ED. Validation of a Doppler technique for beat-to-beat measurement of cardiac output. Clin Sci $1985 ; 69: 377-82$.

21 Denison DM, Edwards RHT, Jones G, Pope H. Estimates of the $\mathrm{CO}_{2}$ pressures in systemic arterial blood during rebreathing on exercise. Respir Physiol 1971;11:186-96.

22 Bevegard S, Holmgren A, Jonsson B. The effect of body position on the circulation at rest and during exercise, with special reference to the influence on stroke volume. Acta Physiol Scand 1960;49:279-98.

23 Reeves JT, Grover RF, Blount G, Filley GF. Cardiac output response to standing and treadmill walking. $J$ Appl Physiol 1961;16:283-8.

24 Hossack KF, Bruce RA, Green B, Kusumi F, DeRouen TA, Trimble S. Maximal cardiac output during upright exercise: approximate normal standards and variations with coronary heart disease. Am $J$ Cardiol 1980;46:204-12.

25 Hossack KF, Kusumi F, Bruce RA. Approximate normal standards of maximal cardiac output during upright exercise in women. Am J Cardiol 1981;47:1080-6.

26 Hickam JB, Cargill WH, Golden A. Cardiovascular reactions to emotional stimuli. Effect on the cardiac output, arteriovenous oxygen difference, arterial pressure, and peripheral resistance. J Clin Invest 1948; 27:290-8.

27 Astrand P-O, Cuddy TE, Saltin B, Stenberg J. Cardiac output during submaximal and maximal work. J Appl Physiol 1964:19:268-74.

28 Higginbotham MB, Morris KG, Coleman RE, Cobb FR. Sex-related differences in the normal cardiac response to upright exercise. Circulation 1984;70:357-66.

29 Hossack KF, Bruce RA. Maximal cardiac function in sedentary normal men and women: comparison of agerelated changes. J Appl Physiol 1982;53:799-804.

30 Davidson FF, Glazier JB, Murray JF. The components of the alveolar-arterial oxygen tension difference in normal subjects and in patients with pneumonia and obstructive lung disease. Am J Med 1972;52:754-62.

31 Wang Y, Marshall RJ, Shepherd JT. The effect of changes in posture and of graded exercise on stroke volume in man. J Clin Invest 1960;39:1051-61.

32 Daley PJ, Sagar KB, Wann LS. Doppler echocardiographic:measurement of flow velocity in the ascending aorta during supine and upright exercise. Br Heart J 1985;54:562-7.

33 Davies NJH. The clinical uses of respiratory mass spectrometry. DM thesis, University of Oxford, 1980.

34 Cotes JE. Lung function: principles and assessment in medicine. 4th ed. Oxford: Blackwell Scientific Publications, 1979. 